University of Nebraska - Lincoln

DigitalCommons@University of Nebraska - Lincoln

\title{
Remote sensing of fuel moisture content from ratios of narrow- band vegetation water and dry-matter indices
}

\author{
Lingli Wang \\ George Mason University \\ E. Raymond Hunt Jr \\ USDA-ARS, Raymond.Hunt@ars.usda.gov \\ John J. Qu \\ George Mason University \\ Xianjun Hao \\ George Mason University \\ Craig S.T. Daughtry \\ USDA-ARS
}

Follow this and additional works at: https://digitalcommons.unl.edu/usdaarsfacpub

Wang, Lingli; Hunt, E. Raymond Jr; Qu, John J.; Hao, Xianjun; and Daughtry, Craig S.T., "Remote sensing of fuel moisture content from ratios of narrow-band vegetation water and dry-matter indices" (2013).

Publications from USDA-ARS / UNL Faculty. 1175.

https://digitalcommons.unl.edu/usdaarsfacpub/1175

This Article is brought to you for free and open access by the U.S. Department of Agriculture: Agricultural Research Service, Lincoln, Nebraska at DigitalCommons@University of Nebraska - Lincoln. It has been accepted for inclusion in Publications from USDA-ARS / UNL Faculty by an authorized administrator of DigitalCommons@University of Nebraska - Lincoln. 


\title{
Remote sensing of fuel moisture content from ratios of narrow-band vegetation water and dry-matter indices
}

\author{
Lingli Wang a, E. Raymond Hunt Jr. ${ }^{\text {b,* }}$, John J. Qu ${ }^{\text {a }}$, Xianjun Hao ${ }^{\text {a }}$, Craig S.T. Daughtry ${ }^{\text {b }}$ \\ a Environmental Science and Technology Center, Department of Geography and GeoInformation Science, College of Science, George Mason University, Fairfax, VA, USA \\ ${ }^{\mathrm{b}}$ USDA-ARS Hydrology and Remote Sensing Laboratory, Beltsville, MD, USA ${ }^{1}$
}

\section{A R T I C L E I N F O}

\section{Article history:}

Received 26 March 2012

Received in revised form 9 October 2012

Accepted 10 October 2012

Available online 28 November 2012

\section{Keywords:}

Fuel moisture content

Spectral reflectance

Normalized Dry Matter Index

Normalized Difference Infrared Index PROSPECT

SAIL

\begin{abstract}
A B S T R A C T
Fuel moisture content (FMC) is an important variable for predicting the occurrence and spread of wildfire. Because FMC is calculated from the ratio of canopy water content to dry-matter content, we hypothesized that FMC may be estimated by remote sensing with a ratio of a vegetation water index to a vegetation dry-matter index. Four vegetation water indices, six dry-matter indices, and the resulting water/dry-matter index ratios were calculated using simulated leaf reflectances from the PROSPECT model. Two water indices, the Normalized Difference Infrared Index (NDII) and the Normalized Difference Water Index (NDWI), were more correlated with leaf water content than with FMC, and were not correlated with leaf dry-matter content. Two dry-matter indices, the Normalized Dry Matter Index (NDMI) and a recent index (unnamed) were correlated to leaf dry matter content, were inversely correlated with FMC, and were not correlated with water content. Ratios of these water indices and these dry-matter indices were highly and consistently correlated with FMC. Ratios of other water indices with other dry-matter indices were not consistently correlated with FMC. The ratio of NDII with NDMI was strongly related to FMC by a quadratic polynomial equation with an $R^{2}$ of 0.947 . Spectral reflectance data were acquired for single leaves and leaf stacks of Quercus alba, Acer rubrum, and Zea mays; the relationship between FMC and NDII/NDMI had an $R^{2}$ of 0.853 and was almost identical to the equation from the PROSPECT model simulations. For the SAIL model simulations, the relationship between NDII/NDMI and FMC at the canopy scale had an $R^{2}$ of 0.900 , but the quadratic polynomial equation differed from the equations determined from the PROSPECT simulations and spectral reflectance data. NDMI requires narrow-band sensors to measure the effect of dry matter on reflectance at $1722 \mathrm{~nm}$ whereas NDII may be determined with many different sensors. Therefore, monitoring FMC with NDII/NDMI requires either a new sensor or a combination of two sensors, one with high temporal resolution for monitoring water content and one with high spectral resolution for estimating dry-matter content.
\end{abstract}

Published by Elsevier Inc.

\section{Introduction}

Fuel moisture content (FMC) is one of the main parameters for predicting the occurrence and spread of wildfire, because it is a critical variable for both fire ignition and fire propagation (Hardy \& Burgan, 1999; Keane et al., 2010; Rollins et al., 2004). FMC is the mass of water per unit mass of dry matter in vegetation (Ceccato et al., 2003; Chuvieco et al., 2002). As the foliar water content in vegetation canopies decreases, there is decreased absorption of shortwave-infrared radiation, which may be monitored with remotely sensed data (Hunt \& Rock, 1989; Tucker, 1980; Ustin et al., in press). A major problem restricting the use of remote sensing for estimating FMC is determining the amount of dry matter in fresh leaves, because many species of concern for fire management have more variation in leaf dry-matter content than variation in leaf water content (Ceccato et al., 2003).

\footnotetext{
* Corresponding author. Tel.: +1 301504 5278; fax: +1 3015048931

E-mail address: Raymond.Hunt@ars.usda.gov (E.R. Hunt).

${ }^{1}$ USDA is an equal opportunity provider and employer.
}

Currently, the most promising approach is retrieval of FMC by inversion using leaf and canopy radiative-transfer models because leaf water and dry-matter contents are model parameters (Riaño et al., 2005; Yebra \& Chuvieco, 2009; Yebra et al., 2008; Zarco-Tejada et al., 2003). However, spectral indices have one advantage enabling rapid analysis of large volumes of remotely sensed data. A number of studies have found that vegetation water indices are correlated with FMC because of the liquid water term in the numerator of FMC (Ceccato et al., 2003; Chuvieco et al., 2002; Dennison et al., 2005; Roberts et al., 2006). There are a large number of potential indices for estimating either liquid water or dry-matter contents, several of which are listed in Table 1. Half of the dry-matter indices in Table 1 were originally developed to detect crop residue or non-photosynthetic vegetation based on the absorption features of lignin and cellulose. Wang et al. (2011a, 2011b) recently proposed the Normalized Dry Matter Index (NDMI, Table 1 ) based on the $\mathrm{C}-\mathrm{H}$ bond stretch overtone at $1722 \mathrm{~nm}$ (Peterson \& Hubbard, 1992). C - H bonds are found in all leaf biochemical constituents: carbohydrates (including cellulose), lignin, proteins, lipids and nucleic acids. 
Table 1

Spectral indices for dry-matter (type = D) and water content (type $=\mathrm{W}$ ) in leaves and canopies.

\begin{tabular}{|c|c|c|c|c|}
\hline Index & Abbreviation & Type & Equation $^{a}$ & Reference \\
\hline Normalized Dry Matter Index & NDMI & $\mathrm{D}$ & $\left(\rho_{1649}-\rho_{1722}\right) /\left(\rho_{1649}+\rho_{1722}\right)$ & Wang et al. (2011a, 2011b) \\
\hline Normalized Difference Tillage Index & NDTI & $\mathrm{D}$ & $\left(\rho_{1650}-\rho_{2215}\right) /\left(\rho_{1650}+\rho_{2215}\right)$ & van Deventer et al. (1997) \\
\hline Cellulose Absorption Index & CAI & $\mathrm{D}$ & $0.5\left(\rho_{2031}-\rho_{2211}\right)-\rho_{2101}$ & Nagler et al. (2000) \\
\hline Normalized Difference Lignin Index & NDLI & $\mathrm{D}$ & {$\left[\log \left(1 / \rho_{1754}\right)-\log \left(1 / \rho_{1680}\right)\right] /\left[\log \left(1 / \rho_{1754}\right)+\log \left(1 / \rho_{1680}\right)\right]$} & Serrano et al. (2002) \\
\hline Normalized Difference Nitrogen Index & NDNI & $\mathrm{D}$ & {$\left[\log \left(1 / \rho_{1510}\right)-\log \left(1 / \rho_{1680}\right)\right] /\left[\log \left(1 / \rho_{1510}\right)+\log \left(1 / \rho_{1680}\right)\right]$} & Serrano et al. (2002) \\
\hline Ligno-Cellulose Absorption Index & LCA & $\mathrm{D}$ & $2 \rho_{2205}-\left(\rho_{2165}+\rho_{2330}\right)$ & Daughtry et al. (2005) \\
\hline Shortwave Infrared Normalized Difference Residue Index & SINDRI & $\mathrm{D}$ & $\left(\rho_{2210}-\rho_{2260}\right) /\left(\rho_{2210}+\rho_{2260}\right)$ & Serbin et al. (2009) \\
\hline Dry Matter Content Index ${ }^{\mathrm{b}}$ & $\mathrm{DMCI}$ & $\mathrm{D}$ & $\left(\rho_{2305}-\rho_{1495}\right) /\left(\rho_{2305}+\rho_{1495}\right)$ & Romero et al. (2012) \\
\hline Normalized Difference Infrared Index & NDII & W & $\left(\rho_{860}-\rho_{1650}\right) /\left(\rho_{860}+\rho_{1650}\right)$ & Hardisky et al. (1983) \\
\hline Reciprocal of Moisture Stress Index & RMSI & W & $\rho_{860} / \rho_{1650}$ & Hunt and Rock (1989) \\
\hline Normalized Difference Water Index & NDWI & W & $\left(\rho_{860}-\rho_{1240}\right) /\left(\rho_{860}+\rho_{1240}\right)$ & Gao (1996) \\
\hline Simple Ratio Water Index & SRWI & W & $\rho_{860} / \rho_{1240}$ & Zarco-Tejada et al. (2003) \\
\hline
\end{tabular}

${ }^{\mathrm{a}} \rho$ is reflectance and the subscript is wavelength $(\mathrm{nm})$.

b Romero et al. (2012) did not name this index; the name used here is for convenience only.

Because FMC is the ratio of water content to dry-matter content, we hypothesized that a ratio of a remotely-sensed water index to a remotely-sensed dry-matter index would better estimate FMC compared to either water indices or dry-matter indices separately. Ideally, dry-matter indices would be highly correlated with dry-matter content and not correlated with water content. Furthermore, ideal water indices would be highly correlated with water content and not correlated with dry-matter content. With an index ratio, many of the factors that affect both the water and dry-matter indices may cancel out, such as leaf structure, leaf angle distribution (LAD), and Leaf Area Index (LAI). The problem is that both water and dry-matter indices are both formulated using wavelengths in the shortwave infrared, so ratios of different water and dry-matter indices need to be evaluated. Radiative-transfer model simulations at the leaf scale were used to test this hypothesis; results of the simulations were then evaluated with spectral reflectance data acquired in the laboratory. Finally, radiative-transfer model simulations at the canopy scale were used to assess the potential for estimating FMC from satellites.

\section{Methods}

\subsection{Remote sensing indices for FMC}

Leaf FMC (dimensionless) was estimated from the ratio of leaf water content $C_{\mathrm{w}}\left(\mathrm{g} \mathrm{cm}^{-2}\right)$ to leaf dry-matter content $C_{\mathrm{m}}\left(\mathrm{g} \mathrm{cm}^{-2}\right)$. Eqs. (1)-(3) were used to calculate $C_{\mathrm{w}}, C_{\mathrm{m}}$ and FMC:

$C_{\mathrm{w}}=\left(W_{\mathrm{f}}-W_{\mathrm{d}}\right) / A$

$C_{\mathrm{m}}=W_{\mathrm{d}} / A$

$\mathrm{FMC}=\left(W_{\mathrm{f}}-W_{\mathrm{d}}\right) / W_{\mathrm{d}}=C_{\mathrm{w}} / C_{\mathrm{m}}$

where: $W_{\mathrm{f}}$ was the leaf fresh weight $(\mathrm{g}), W_{\mathrm{d}}$ was the leaf dry weight $(\mathrm{g})$, and $A$ was the leaf area $\left(\mathrm{cm}^{2}\right)$. Canopy $C_{\mathrm{w}}$ and $C_{\mathrm{m}}$ were the leaf $C_{\mathrm{w}}$ and $C_{\mathrm{m}}$ multiplied by Leaf Area Index (LAI). The ratio of $C_{\mathrm{w}} / C_{\mathrm{m}}$ was used for both leaves and canopies because leaf area canceled out.

Besides NDMI, other indices related to dry-matter content were selected (Table 1): the Normalized Difference Tillage Index (NDTI; van Deventer et al., 1997), the Cellulose Absorption Index (CAI; Nagler et al., 2000), the Normalized Difference Lignin Index (NDLI; Serrano et al., 2002), the Normalized Difference Nitrogen Index (NDNI; Serrano et al., 2002), the Lingo-Cellulose Absorption Index (LCA; Daughtry et al., 2005), and the Shortwave Infrared Normalized Difference Residue Index (SINDRI; Serbin et al., 2009). Furthermore, we used a recently-published unnamed index from Romero et al. (2012), which for convenience was called the Dry Matter Content Index (DMCI) for this study (Table 1).
Two normalized-difference indices and two ratio indices were selected for analysis of leaf water content (Table 1 ), with one normalized-difference index and one ratio index based on the local absorption maximum of liquid water at $1240 \mathrm{~nm}$, and one normalized-difference index and one ratio index based on the local absorption minimum at $1650 \mathrm{~nm}$. The indices were the Normalized Difference Infrared Index (NDII; Hardisky et al., 1983), the Reciprocal of the Moisture Stress Index (RMSI; Hunt \& Rock, 1989), the Normalized Difference Water Index (NDWI; Gao, 1996), and the Simple Ratio Water Index (SRWI; Zarco-Tejada et al., 2003). RMSI was used instead of the Moisture Stress Index, because RMSI increases with increasing FMC allowing for better comparisons among water/dry-matter index ratios.

\subsection{PROSPECT and SAIL model simulations}

In order to generate water and dry-matter indices for various FMC, the leaf radiative-transfer model, PROSPECT version 4 (Féret et al., 2008; Jacquemoud et al., 2009), was used to simulate leaf reflectance and transmittance from 400 to $2500 \mathrm{~nm}$. For a total of 250 simulations, input parameters $\left(C_{\mathrm{w}}, C_{\mathrm{m}}\right.$ and the leaf parameter $\left.N\right)$ were randomly generated using a uniform distribution within a selected range for each variable (Table 2). Total chlorophyll $a$ and $b$ content $\left(C_{\mathrm{ab}}\right)$ was held constant at $40 \mu \mathrm{g} \mathrm{cm}{ }^{-2}$ because variation of $C_{\mathrm{ab}}$ had no effect on the indices used in Table 1 . The range selected for each parameter was set to exceed all reasonable combinations expected to occur, based on data from ground measurements and the published literature (Féret et al., 2011).

The Scattering by Arbitrarily Inclined Leaves (SAIL) model (Verhoef, 1984) was used to simulate canopy spectral reflectance as a function of leaf reflectance and transmittance, soil background reflectance, LAI, and LAD (Table 2). Spectral reflectances and transmittances from the 250 PROSPECT simulations were used as inputs to the SAIL model. A total of 4500 simulations were made using the 250 PROSPECT simulations, with 6 different LAI and 3 LAD (Table 2). The spectral reflectance of a dry Othello silt loam (fine silty, mixed, active, mesic Typic Endoaquult) from Salisbury, Maryland, was used for the background reflectance (Daughtry, 2001). The background reflectances of this soil caused many of the indices to be unstable at low LAI, therefore only LAI $\geq 1.5$ were used (Table 2 ).

\subsection{Spectral reflectance measurements}

Spectral reflectances of individual leaves and stacks of leaves were used to determine the relationship between FMC and water/ dry-matter index ratios. Leaves of white oak (Quercus alba L.), red maple (Acer rubrum L.) and maize (Zea mays L.) were collected at the USDA-ARS Beltsville Agricultural Research Center, Beltsville, MD. Leaves (many more than were necessary for the measurements) 
Table 2

Input parameters for PROSPECT and SAIL model simulations. The parameters for PROSPECT simulations were randomly selected to obtain variation in water and dry-matter contents. The leaf reflectances and transmittances from the PROSPECT simulations were inputs for the SAIL model simulations.

\begin{tabular}{|c|c|c|}
\hline Model & Parameters & Values \\
\hline \multirow{4}{*}{$\begin{array}{l}\text { PROSPECT } \\
\qquad(n=250)\end{array}$} & Leaf structure parameter $(N)$ & $1-3$ \\
\hline & $\begin{array}{l}\text { Chlorophyll content } \\
\left(C_{\mathrm{ab}}, \mu \mathrm{g} \mathrm{cm}^{-2}\right)\end{array}$ & 40 \\
\hline & Water content $\left(C_{\mathrm{w}}, \mathrm{g} \mathrm{cm}^{-2}\right)$ & $0.004-0.034$ \\
\hline & $\begin{array}{l}\text { Dry matter content } \\
\left(C_{\mathrm{m}}, \mathrm{g} \mathrm{cm}^{-2}\right)\end{array}$ & $0.002-0.018$ \\
\hline \multirow{8}{*}{$\begin{array}{l}\text { SAIL } \\
\qquad(n=4500)\end{array}$} & Leaf Area Index (LAI) & $1.5,2.0,3.0,4.0,5.0$, and 6.0 \\
\hline & Leaf angle distribution (LAD) & $\begin{array}{l}\text { Erectophile, spherical, and } \\
\text { planophile }\end{array}$ \\
\hline & Fraction of direct solar irradiance & 0.8 \\
\hline & Background reflectance & Othello silt-loam \\
\hline & Solar declination & $0^{\circ}$ \\
\hline & Latitude & $36^{\circ}$ \\
\hline & View zenith angle & Nadir \\
\hline & Time of day & 10:00 AM \\
\hline
\end{tabular}

were placed into sealable plastic bags and then placed into an insulated cooler, in order to minimize water loss per leaf during transport to the laboratory. Directional-hemispherical spectral reflectances of the adaxial leaf surface were measured with an Analytical Spectral Devices FieldSpec 3 Portable Spectroradiometer (Analytical Spectral Devices, Inc., Boulder, Colorado, USA) and an LI-1800-12 Integrating Sphere (LiCor, Inc., Lincoln, Nebraska, USA). Leaf fresh and dry weights were measured to the nearest $0.1 \mathrm{mg}$ using an analytical balance and leaf area was measured with a LiCor LI-3100c Area Meter.

Spectral reflectances were measured on ten single leaves of white oak, red maple and corn immediately upon return to the laboratory. Then, the leaves were placed on a laboratory bench to lose water, so that different $C_{\mathrm{w}}$ could be measured for each $C_{\mathrm{m}}$. At frequent intervals (about 30-45 min), weight and spectral reflectances were re-measured. Finally, the leaves were dried in an oven at $50{ }^{\circ} \mathrm{C}$ for $24 \mathrm{~h} ; C_{\mathrm{w}}, C_{\mathrm{m}}$ and FMC were calculated according to Eqs. (1)-(3). A total of 140 spectral measurements were made on the 30 leaves.

In separate experiments, 15 leaves of white oak and red maple were collected to create three 2-leaf stacks and three 3-leaf stacks. Spectral reflectances of the leaf stacks were made using the spectrometer and integrating sphere. Compared to a single leaf, a leaf stack would have the same FMC, but higher $C_{\mathrm{w}}$ and $C_{\mathrm{m}}$, so correlations of FMC with water or dry-matter indices would be reduced. Then, the leaf stacks were placed on the laboratory bench to lose water. The stacks were kept together for a total of 102 measurements. At the end of the experiments, area and dry weight were measured for each leaf.

\subsection{Statistical approaches}

Correlation coefficients $(r)$ were used to determine the association among various leaf water indices, dry-matter indices, and their ratios to the PROSPECT input parameters $\left(C_{\mathrm{w}}, C_{\mathrm{m}}\right.$ and the leaf parameter $N$ ) and to FMC (Sokal \& Rohlf, 1995). Least square regressions of the index ratios were tested for predicting FMC. Various mathematical transformations of the independent and dependent variables were made to determine if simple linear regressions may be used, but the results were not good. Therefore, polynomial regressions were used to quantify the relationships between FMC and the water/dry-matter index ratios:

$$
\begin{aligned}
\mathrm{FMC}= & b_{3}(\text { water } / \text { dry }- \text { matter index })^{3} \\
& +b_{2}(\text { water } / \text { dry }- \text { matter index })^{2} \\
& +b_{1}(\text { water } / \text { dry }- \text { matter index })+b_{0}
\end{aligned}
$$

where: $b_{3}, b_{2}, b_{1}$, and $b_{0}$ are the regression coefficients; the water index is either NDII, NDWI, RMSI, or SRWI; and the dry-matter index is either NDMI, NDTI, CAI, NDLI, NDNI, LCA, SINDRI, or DMCI (Table 1). The performance of each water/dry-matter index was evaluated by the coefficient of determination $\left(R^{2}\right)$ and the root mean square error (RMSE). Two components of RMSE, systematic and unsystematic, were calculated to evaluate regression model performance (Willmott, 1981).

\section{Results}

\subsection{Simulations using the PROSPECT model}

Two dry-matter indices (NDMI and DMCI) were highly correlated with leaf dry-matter content, but had smaller correlations with FMC (Table 3). Furthermore, the correlation coefficients had opposite signs with respect to FMC and dry-matter content (Table 3), which was consistent with their definitions (Table 1). NDMI and DCMI were not correlated with leaf water content; however, five of the proposed dry-matter indices (NDTI, NDLI, NDNI, LCA, and SINDRI) were more correlated with water content than with dry-matter content (Table 3). All 4 water indices were highly correlated to water content, were not correlated to dry-matter content, and had lower correlations with FMC compared to the correlations with water content (Table 3).

In contrast to single indices, FMC was highly and consistently correlated with ratios of the four water indices (NDII, NDWI, RMSI, and SWRI) to either NDMI or DMCI (Table 4). Ratios of the water indices with LCA were consistently correlated with FMC, but the correlation coefficients were lower, and ratios of water indices with either CAI or SINDRI were not correlated with FMC.

All ratios of the four water-content indices with the dry-matter indices, NDTI, NDLI and NDNI, were expected to have positive correlations, but correlations among FMC and the index ratios were not consistent (Table 4). Whereas the ratios of NDWI/NDTI, NDII/NDTI, NDWI/NDLI, and NDII/NDLI were positively correlated with FMC, the correlations of FMC with either SWRI/NDTI or SWRI/NDLI were negative, and there was no correlation of FMC with either RMSI/ NDTI or RMSI/NDLI (Table 4). The correlation coefficients for water-index/NDNI ratios were significantly negative for ratios with three of the four water indices (Table 4). The negative correlations may be an indication that any positive correlations with FMC may have been spurious.

The six water/dry-matter indices with the highest correlations from Table 4 were assessed for the potential to predict FMC based on the PROSPECT simulations (Fig. 1). The relationships with FMC were nonlinear and polynomial regressions yielded the smallest RMSE and the highest $R^{2}$ (Fig. 1). Cubic polynomial equations were

Table 3

Correlations of the indices for water and dry-matter content with leaf parameters and fuel moisture content from PROSPECT model simulations $(n=250)$. Critical values of the correlation coefficient $(r)$ are 0.123 for $P=0.95$ and 0.165 for $P=0.99$.

\begin{tabular}{llclc}
\hline Index & $\begin{array}{l}\text { Leaf structure } \\
\text { parameter }(N)\end{array}$ & $\begin{array}{l}\text { Dry matter } \\
\text { content }\left(C_{\mathrm{m}}\right)\end{array}$ & $\begin{array}{l}\text { Water } \\
\text { content }\left(C_{\mathrm{w}}\right)\end{array}$ & $\begin{array}{l}\text { Fuel moisture } \\
\text { content }(\mathrm{FMC})\end{array}$ \\
\hline NDMI & -0.326 & 0.897 & -0.0349 & -0.599 \\
NDTI & -0.500 & 0.279 & 0.792 & 0.274 \\
CAI & -0.306 & 0.458 & 0.119 & -0.119 \\
NDLI & 0.287 & 0.112 & 0.902 & 0.456 \\
NDNI & 0.121 & -0.287 & 0.897 & 0.684 \\
LCA & 0.759 & -0.100 & -0.626 & -0.268 \\
SINDRI & 0.0794 & 0.531 & -0.832 & -0.808 \\
DMCI & 0.394 & -0.847 & 0.102 & 0.589 \\
NDII & -0.381 & 0.0628 & 0.919 & 0.478 \\
RMSI & -0.406 & 0.0496 & 0.899 & 0.476 \\
NDWI & -0.382 & -0.106 & 0.927 & 0.593 \\
SWRI & -0.386 & -0.108 & 0.923 & 0.595 \\
\hline
\end{tabular}


Table 4

Correlations of water-index/dry-matter-index ratios with fuel moisture content (FMC) from PROSPECT model simulations $(n=250)$. The water-index numerator is shown along the columns and the dry-matter-index denominator is shown along the rows. The value in each cell is the correlation coefficient $(r)$ between FMC and the water/ dry-matter index (column/row). Critical values of $r$ are 0.123 for $P=0.95$ and 0.165 for $P=0.99$.

\begin{tabular}{lrrrr}
\hline \multirow{2}{*}{ Dry-matter index } & \multicolumn{2}{l}{ Water index } & & \\
\cline { 2 - 5 } & NDWI & \multicolumn{1}{c}{ NDII } & \multicolumn{1}{c}{ SWRI } & \multicolumn{1}{c}{ RMSI } \\
\hline NDMI & 0.966 & 0.961 & 0.716 & 0.899 \\
NDTI & 0.809 & 0.734 & -0.207 & 0.064 \\
CAI & -0.097 & -0.091 & -0.083 & -0.087 \\
NDLI & 0.523 & 0.356 & -0.335 & 0.010 \\
NDNI & 0.166 & -0.126 & -0.537 & -0.478 \\
LCA & 0.369 & 0.308 & 0.256 & 0.279 \\
SINDRI & 0.048 & 0.049 & 0.046 & 0.047 \\
DMCI & -0.922 & -0.903 & -0.689 & -0.882 \\
\hline
\end{tabular}

better for NDWI/DMCI (Fig. 1B) and NDII/DMCI (Fig. 1D), whereas quadratic polynomial equations were better for the other water/ dry-matter indices (Fig. 1A,C,E, and F). The critical range for predicting FMC is from about 0.3 to 1.2 (30\% to $120 \%$; Jolly, 2007), so while RMSI/NDMI (Fig. 1E) had the highest $R^{2}$ and lowest RMSE overall, there was much more scatter at low FMC than at high FMC.

\subsection{Spectral reflectances of drying leaves and leaf stacks}

With a few exceptions, correlations among indices and FMC from spectral reflectance data (Tables 5 and 6 ) followed the same trends as the correlations from the PROSPECT simulations (Tables 3 and 4). Two dry-matter indices, NDMI and DMCI, were highly correlated with dry-matter content, and were inversely correlated with FMC, although NDMI had a small negative correlation with water content (Table 5). The four water indices were significantly correlated with water content and FMC, and were not significantly correlated with dry-matter content (Table 5). Furthermore, the correlations of the four water indices with water content were higher than the correlations with FMC. NDII had the highest correlation with water content; two dry-matter indices (NDTI and NDNI) had higher correlations with water content than the other three water indices (Table 5).

Ratios of water indices to NDMI had consistently the highest correlations with FMC, particularly NDII/NDMI (Table 6). Ratios of water indices to DMCI had significant negative correlations with FMC as expected. Whereas index ratios with CAI and SINDRI were not significantly correlated with FMC in the PROSPECT simulations (Table 4), the ratios of water indices to SINDRI were positively correlated with FMC, and the ratios of water indices to CAI were negatively correlated to FMC (Table 6). Similar to the PROSPECT simulations (Tables 3 and 4), the ratios of the four water indices (NDII, NDWI, RMSI, and SWRI) with NDMI (Table 6) had much higher correlations with FMC than did the individual indices (Table 5).

Because the water/dry-matter index ratio, NDII/NDMI, had the highest correlation with FMC using the spectral reflectance data (Table 6), NDII/NDMI was used to predict FMC using a polynomial regression (Fig. 2). With single-leaf and stacked-leaf datasets pooled, FMC was best predicted with a quadratic polynomial regression (Table 7). Furthermore, the coefficients from polynomial regression were almost identical to those from the PROSPECT simulations (Fig. 1D, Table 7).

Pooled data may have spurious correlations when no actual correlation exists within the individual datasets, so the datasets were analyzed separately (Fig. 2). The quadratic regression equations from both the pooled spectral reflectance data and the PROSPECT simulations (Table 7) were similar for each dataset (Fig. 2). There was little variation of either FMC or NDII/NDMI for leaves and leaf-stacks of Q. alba (Fig. 2A), so the number of terms for a polynomial regression could not be determined. However, the quadratic regression equations from the pooled data and from the PROSPECT simulations went through the centers of the point clusters (Fig. 2A). In contrast, there were large ranges of variation in both FMC and NDII/NDMI for $A$. rubrum (Fig. 2B) and Z. mays (Fig. 2C), and the quadratic equations fitted the data for both species.

RMSE for predicted FMC from the pooled regression equation was 0.307 and RMSE from the PROSPECT simulations was 0.560 (Table 7). However for the $Q$. alba and A. rubrum datasets individually, predicted FMC had a range of RMSE from 0.126 to 0.195 using the pooled regression equation and had a range of 0.137 to 0.259 using the regression from the PROSPECT simulations (Table 8). The larger overall RMSE for the two equations was from the $Z$. mays leaf data, which had RMSE of 0.910 for the pooled regression equation and 0.919 for the equation from the PROSPECT simulations (Table 8).

Because the regression equations were not derived for each reflectance dataset, RMSE for each dataset included both random, unsystematic errors and biased, systematic errors (Table 8). The unbiased RMSE was greater than systematic RMSE for each dataset using the pooled regression equation (Table 8 ). Therefore, pooling the spectral reflectance data to determine a single regression equation was valid. Except for the A. rubrum leaf data, systematic RMSE was greater than unbiased RMSE using the regression from the PROSPECT simulations (Table 8).

\subsection{Simulations using the SAIL model}

In contrast to the PROSPECT simulations (Table 4) and the spectral reflectance data (Table 6), all of the water/dry-matter index ratios were significantly correlated with FMC from the SAIL model simulations (Table 9). Furthermore, the correlations were positive or negative as expected from the index definitions (Table 1). The index ratios with the highest correlations with simulated FMC were NDII/NDMI and RMSI/NDMI (Table 9).

The relationship between simulated FMC with NDII/NDMI showed much more scatter overall (Fig. 3) compared to the PROSPECT simulations (Fig. 1D) or the spectral reflectance data (Fig. 2). A quadratic polynomial regression provided the best prediction of FMC (Table 7). Regressions with NDII/NDMI had higher $R^{2}$ and lower RMSE compared to any other water/dry-matter index ratio (data not shown). Whereas the correlation between RMSI/NDMI and FMC was the second highest (Table 9), the quadratic polynomial regression using RMSI/NDMI had negative coefficients for the squared and linear terms, and therefore the equation had no similarity to the regression equation from the PROSPECT simulations (Fig. 1E).

In Fig. 3, the regression lines from the PROSPECT model simulations and the leaf spectral reflectance data predicted lower FMC at a given NDII/NDMI, with more divergence at high FMC (Fig. 3). The effects of LAI and LAD on the regression equation were assessed by including these as independent variables (data not shown). The linear regression coefficients for LAI and LAD were both significant at $P<0.05$, but the two terms together only explained about $1 \%$ of the explained variation, based on a comparison of $R^{2}$, so it was likely that the significance of the LAI and LAD linear terms was caused by the very large number of SAIL model simulations.

Most of the scatter in Fig. 3 is at very high FMC, whereas the important range of FMC is from 0.3 to 1.2 (Jolly, 2007). Using the SAIL model simulations at FMC $\leq 2.0$, FMC was near-linearly related to NDII/NDMI with an $R^{2}$ of 0.890 and an RMSE of 0.167 (data not shown). However, the slope of the regression was higher than the equations for the pooled spectral reflectance data and the PROSPECT simulations, so equations developed at the leaf scale could not be used at the canopy scale. 
A

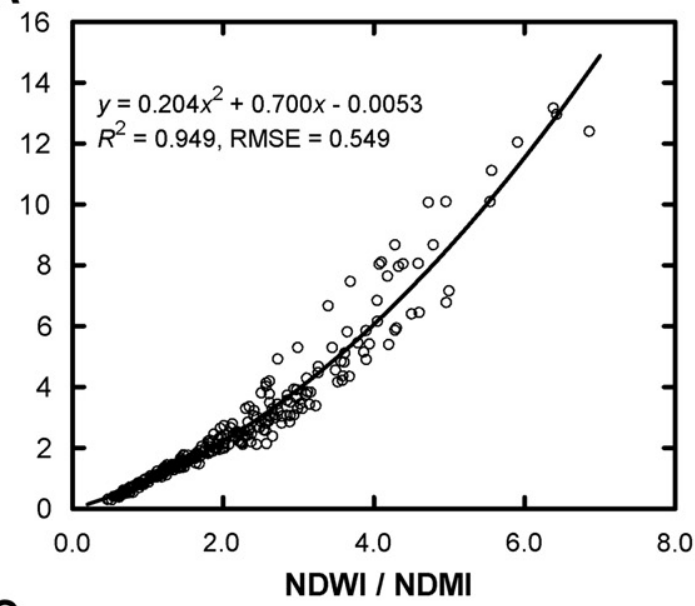

C

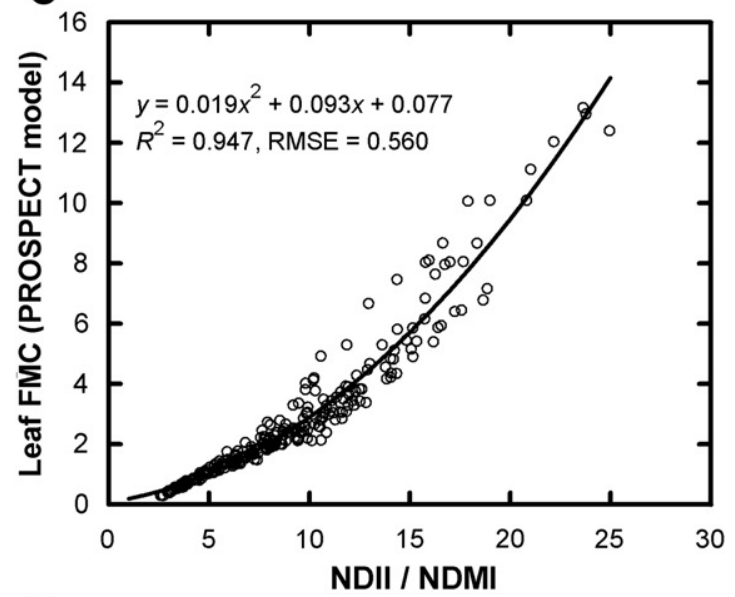

E

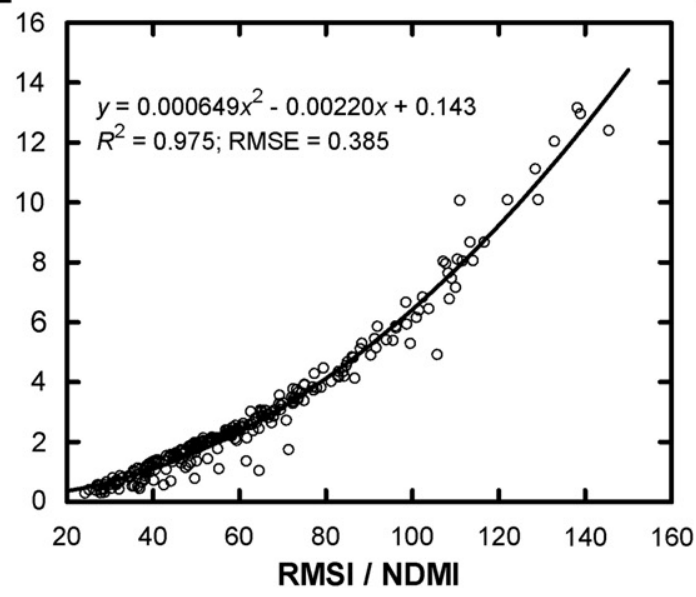

B

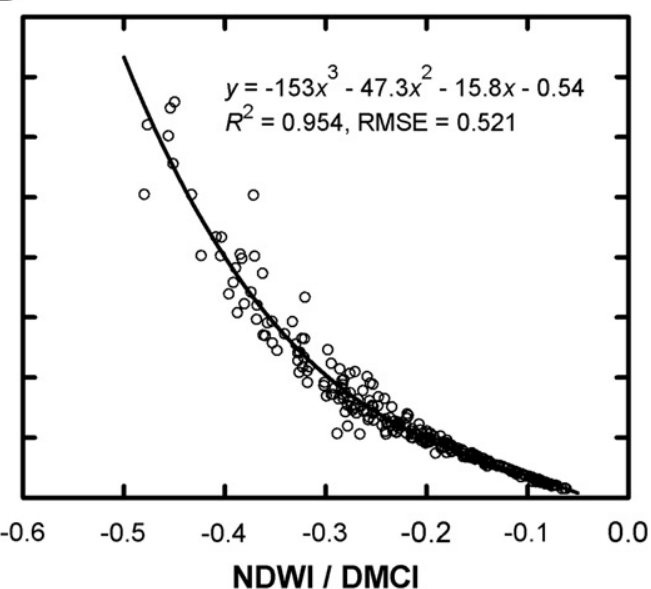

D

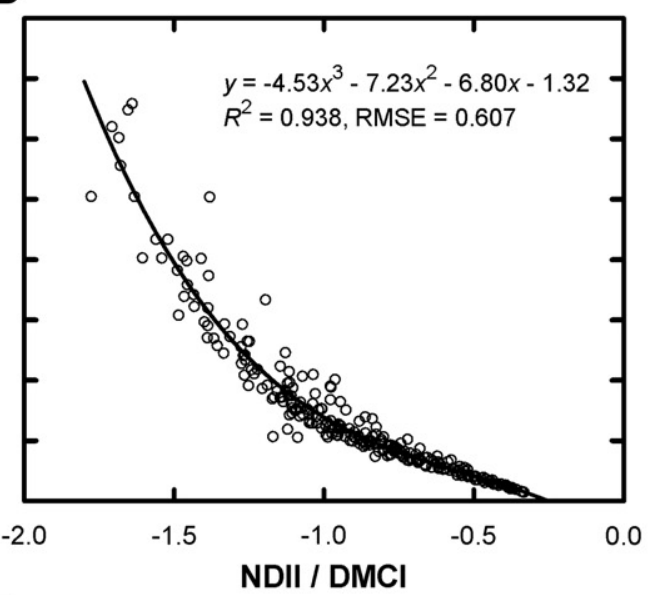

$\mathbf{F}$

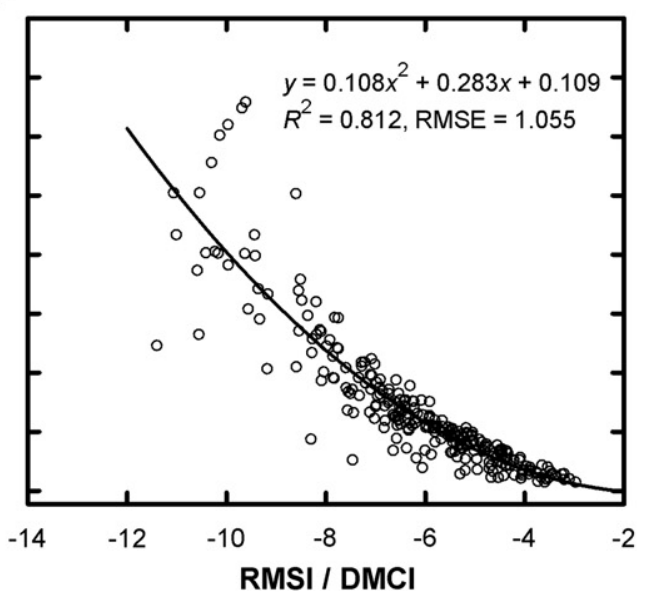

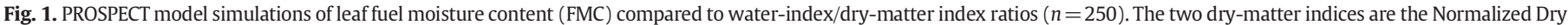

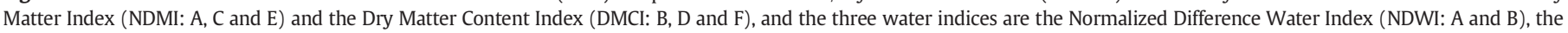

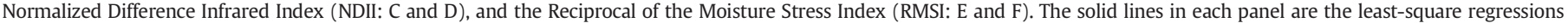
with the coefficient of determination $\left(R^{2}\right)$ and root mean square error (RMSE).

\section{Discussion}

As hypothesized, ratios of vegetation water/dry-matter spectral indices were usually better correlated to FMC than were the water indices or dry-matter indices separately. Ratios of two narrow-band spectral indices were originally tested for assessing crop nitrogen status (Daughtry et al., 2000; Eitel et al., 2008; Haboudane et al., 2002; Zarco-Tejada et al., 2004). Whereas some vegetation indices were highly correlated to chlorophyll content for leaves, the correlations were reduced at the canopy scale because of the effects of LAI, LAD, and soil spectral reflectance. Some other vegetation indices were found to be much more sensitive to canopy structure than they were to chlorophyll content, so ratios of a chlorophyll index with a canopy-structure index were found to be better related to crop nitrogen requirements than single vegetation indices (Daughtry et al., 2000; Eitel et al., 2008; Haboudane et al., 2002; Zarco-Tejada et al., 2004). This study was the first to test index ratios for FMC estimation; furthermore, the indices were selected based on their previously- 
Table 5

Correlations of water and dry-matter indices from spectral reflectances of drying leaves of Quercus alba, Acer rubrum and Zea mays, and from spectral reflectances of leaf stacks of $Q$. alba and A. rubrum ( $n=242$ ). Stacks of 2 or 3 leaves have the same FMC, but higher $C_{\mathrm{w}}$ and $C_{\mathrm{m}}$ compared to single leaves. Critical values of $r$ are 0.123 for $P=0.95$ and 0.165 for $P=0.99$.

\begin{tabular}{lcrr}
\hline $\begin{array}{l}\text { Index or index } \\
\text { ratio }\end{array}$ & $\begin{array}{l}\text { Dry-matter content } \\
\left(C_{\mathrm{m}}\right)\end{array}$ & $\begin{array}{l}\text { Water content } \\
\left(C_{\mathrm{w}}\right)\end{array}$ & $\begin{array}{l}\text { Fuel moisture content } \\
(\text { FMC })\end{array}$ \\
\hline NDMI & 0.726 & -0.262 & -0.562 \\
NDTI & 0.452 & 0.559 & 0.009 \\
CAI & 0.350 & 0.322 & 0.312 \\
NDLI & -0.057 & 0.227 & -0.183 \\
NDNI & 0.062 & 0.525 & 0.251 \\
LCA & -0.522 & -0.342 & -0.314 \\
SINDRI & 0.307 & 0.026 & -0.358 \\
DMCI & -0.802 & 0.119 & 0.508 \\
NDII & -0.0429 & 0.599 & 0.299 \\
RMSI & -0.038 & 0.426 & 0.251 \\
NDWI & -0.00133 & 0.419 & 0.263 \\
SWRI & -0.040 & 0.398 & 0.243 \\
\hline
\end{tabular}

determined biophysical relationships to either foliar water content or dry-matter content.

In general, correlation analyses are difficult to interpret because, by definition for $P<0.05$, about one of 20 correlations of random numbers will be significant. Furthermore, correlations only show the relatedness of two variables (Sokal \& Rohlf, 1995) and do not show causation. The PROSPECT simulations were important in this study because the key input parameters, leaf dry-matter and water contents, were themselves not correlated. As a result, the four water indices used in this study were consistently correlated to water content and were not correlated to dry-matter content. Furthermore, two dry-matter indices (NDMI and DMCI) were consistently correlated to dry-matter content and were not correlated to water content, whereas some other dry-matter indices were actually better correlated with leaf water content. For real leaves, water and dry-matter contents are correlated because both variables are affected by leaf thickness. With the spectral reflectance data, correlations among water content, dry-matter content and FMC were reduced by drying and stacking the leaves. In the SAIL model simulations, there were larger ranges of canopy dry-matter and water contents per ground area because of the range in LAI. However, the expected correlations between canopy dry-matter and canopy water contents caused by variation in LAI were reduced because leaf transmittances and reflectances from the PROSPECT model simulations were used.

From the correlations, two dry-matter-content indices stood out: NDMI (Wang et al., 2011a, 2011b) and DMCI (Romero et al., 2012). The ratio of NDII/NDMI had the highest correlation with FMC from the leaf data (Table 6) and from the SAIL model simulations (Table 9),

Table 6

Correlations of water-index/dry-matter-index ratios with fuel moisture content (FMC) from the spectral reflectance data $(n=242)$. The water-index numerator is shown along the columns and the dry-matter-index denominator is shown along the rows. The value in each cell is the correlation coefficient $(r)$ between FMC and the water/ dry-matter index (column/row). Critical values of $r$ are 0.123 for $P=0.95$ and 0.165 for $P=0.99$.

\begin{tabular}{lrrrr}
\hline \multirow{2}{*}{ Dry-matter index } & \multicolumn{2}{l}{ Water index } & & \\
\cline { 2 - 5 } & NDWI & \multicolumn{1}{c}{ NDII } & \multicolumn{1}{c}{ SWRI } & \multicolumn{1}{c}{ RMSI } \\
\hline NDMI & 0.732 & 0.890 & 0.674 & 0.775 \\
NDTI & 0.232 & -0.064 & -0.003 & -0.036 \\
CAI & -0.367 & -0.174 & -0.360 & -0.270 \\
NDLI & 0.282 & 0.199 & -0.041 & 0.047 \\
NDNI & 0.079 & 0.044 & -0.058 & 0.057 \\
LCA & 0.403 & 0.205 & 0.408 & 0.323 \\
SINDRI & 0.498 & 0.469 & 0.478 & 0.474 \\
DMCI & -0.539 & -0.486 & -0.500 & -0.505 \\
\hline
\end{tabular}

A
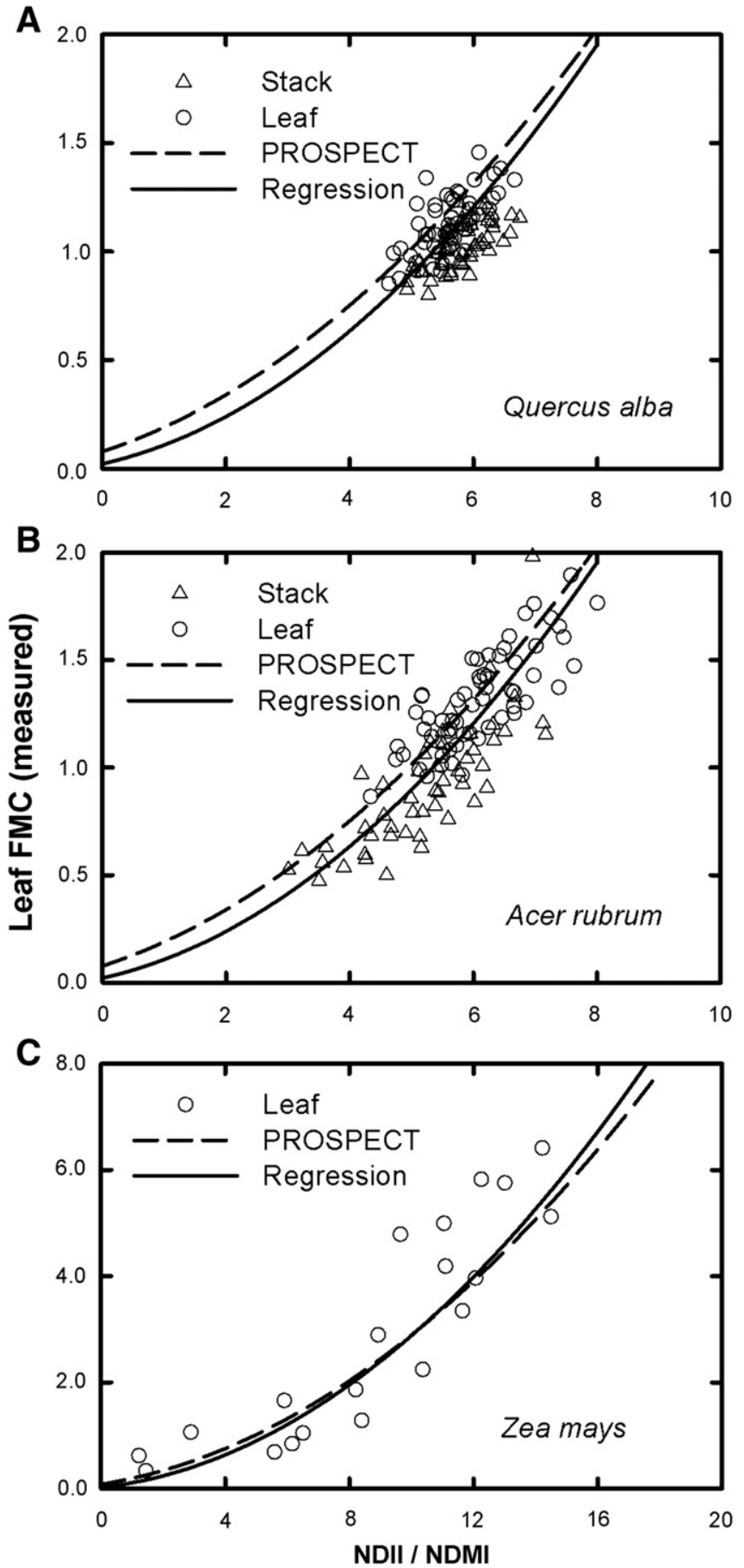

Fig. 2. Measured FMC versus NDII/NDMI calculated from leaf spectral reflectance data for: (A) Q. alba, (B) A. rubrum and (C) Z. mays. Data from leaf stacks were included with the leaf data in (A) Q. alba and (B) A. rubrum. The solid lines show the pooled polynomial regression combining the 5 datasets $(n=242)$ and the dashed lines show the regression equation from the PROSPECT simulations (Table 7).

Table 7

Polynomial regression coefficients and summary statistics for the pooled leaf and leaf-stack spectral reflectance data, PROSPECT leaf model simulations, and SAIL canopy model simulations. The quadratic polynomial equation is FMC $=b_{2}(\mathrm{NDI} / \mathrm{NDMI})^{2}+b_{1}$ $(\mathrm{NDII} / \mathrm{NDMI})+b_{0}$. RMSE, $R^{2}$ and $n$ are the root mean square error, coefficient of determination, and the number of points, respectively.

\begin{tabular}{lllcrrr}
\hline Source & $b_{2}$ & $b_{1}$ & \multicolumn{1}{l}{$b_{0}$} & \multicolumn{1}{l}{$n$} & $R^{2}$ & RMSE \\
\hline Reflectance data & 0.0221 & 0.0645 & 0.0210 & 242 & 0.853 & 0.307 \\
PROSPECT & 0.0188 & 0.0934 & 0.0772 & 250 & 0.947 & 0.560 \\
SAIL & 0.0163 & 0.441 & -0.900 & 4500 & 0.900 & 0.765 \\
\hline
\end{tabular}


Table 8

Comparison of RMSE and component terms, systematic RMSE (RMSE $_{s}$ and unbiased RMSE (RMSE $E_{\mathrm{u}}$ ), for prediction of FMC in each spectral-reflectance dataset using: the pooled polynomial regression equation; and the polynomial regression from the PROSPECT model simulations (Table 7).

\begin{tabular}{llllllll}
\hline \multirow{2}{*}{ Dataset } & \multicolumn{3}{l}{ Pooled data regression } & & \multicolumn{3}{l}{ PROSPECT regression } \\
\cline { 2 - 3 } & RMSE & RMSE $_{\mathrm{s}}$ & RMSE $_{\mathrm{u}}$ & & RMSE & RMSE $_{\mathrm{s}}$ & RMSE $_{\mathrm{u}}$ \\
\hline Q. alba leaves & 0.126 & 0.027 & 0.118 & & 0.137 & 0.133 & 0.116 \\
Q. alba leaf-stack & 0.162 & 0.038 & 0.137 & & 0.256 & 0.160 & 0.129 \\
A. rubrum leaves & 0.178 & 0.034 & 0.176 & & 0.175 & 0.097 & 0.168 \\
A. rubrum leaf-stack & 0.195 & 0.065 & 0.175 & & 0.259 & 0.200 & 0.171 \\
Z. mays leaves & 0.910 & 0.381 & 0.839 & & 0.919 & 0.652 & 0.639 \\
\hline
\end{tabular}

and was among the best water/dry-matter indices from the PROSPECT simulations (Table 4). Not only were the correlations highly significant, they were consistent with the index correlations to water and dry-matter contents (Tables 3 and 5). Furthermore, good correlations were found with the other water/dry-matter index ratios (Tables 4, 6 and 9) indicating that the relationships between NDII/NDMI and FMC were not artifacts from the correlation analyses.

Because FMC is the ratio of water content to dry-matter content, vegetation water indices alone may be used to determine wildfire potential (Ceccato et al., 2003; Chuvieco et al., 2002; Dennison et al., 2005; Roberts et al., 2006). Within similar vegetation types, variations of dry-matter content may be predictable so that FMC may be determined from water indices alone. However, canopy water content varies strongly with LAI (Yilmaz et al., 2008a, 2008b), so reductions of water content detected by remote sensing do not necessarily correspond to reductions of FMC. In this study, NDII was more correlated with water content than FMC and the NDII/NDMI index ratio was more correlated with FMC than water content, which indicated that NDMI adds information for predicting FMC compared to a water index alone. However, NDII is also an important index for the remote sensing of snow cover and flooded areas (Delbart et al., 2005, 2006; Xiao et al., 2002a, 2002b), so NDII/NDMI must be constrained seasonally to be effective at monitoring FMC.

Multiple linear regressions using water indices or inversions of spectral reflectances with MODIS data were able to achieve RMSE about 0.15 for prediction of FMC in chaparral and shrublands (Peterson et al., 2008; Yebra \& Chuvieco, 2009; Yebra et al., 2008). At FMC $\leq 2.0$ for the data of Q. alba and A. rubrum (Table 8) and the SAIL model simulations, predictions of FMC from NDII/NDMI polynomial regressions were accurate within an RMSE from 0.126 to 0.259 , so potential accuracy may be comparable to current methods. However, RMSE was greater than 0.9 for $Z$. mays leaves, so NDII/NDMI will not be useful for some vegetation types at the canopy scale. Furthermore, the effects of different soil background reflectances, particularly wet and dry non-photosynthetic vegetation, need to be evaluated before accuracies of water/dry-matter indices may be assessed.

\section{Table 9}

Correlations of water-index/dry-matter-index ratios with fuel moisture content (FMC) from SAIL model simulations $(n=4500)$. The water-index numerator is shown along the columns and the dry-matter-index denominator is shown along the rows. The value in each cell is the correlation coefficient $(r)$ between FMC and the water/ dry-matter index (column/row). Critical values of $r$ are 0.062 for $P=0.95$ and about 0.081 for $P=0.99$.

\begin{tabular}{lrrrr}
\hline \multirow{2}{*}{ Dry-matter index } & \multicolumn{2}{l}{ Water index } & & \\
\cline { 2 - 5 } & NDWI & \multicolumn{1}{c}{ NDII } & \multicolumn{1}{c}{ SWRI } & \multicolumn{1}{c}{ RMSI } \\
\hline NDMI & 0.706 & 0.952 & 0.760 & 0.950 \\
NDTI & 0.467 & 0.568 & 0.142 & 0.684 \\
CAI & -0.327 & -0.228 & -0.199 & -0.239 \\
NDLI & 0.426 & 0.366 & 0.109 & 0.413 \\
NDNI & 0.456 & 0.359 & 0.400 & 0.397 \\
LCA & 0.403 & 0.350 & 0.353 & 0.360 \\
SINDRI & 0.518 & 0.254 & 0.173 & 0.210 \\
DMCI & -0.597 & -0.755 & -0.445 & -0.691 \\
\hline
\end{tabular}

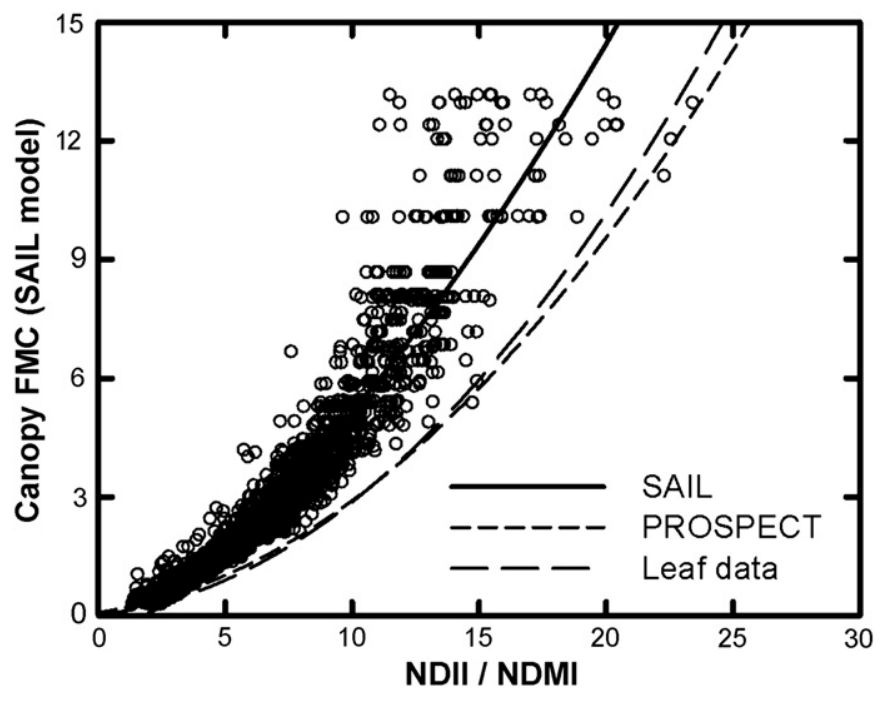

Fig. 3. SAIL model simulations of canopy FMC compared to the NDII/NDMI water-index/dry-matter-index ratio. The solid line shows the polynomial regression equation based on the SAIL model simulations $(n=4500)$ and the dashed lines show the regression equations from the PROSPECT model simulations and leaf spectral reflectance data (Table 7).

The reflectance signal for dry-matter content is weaker than that of water content, in part because the amount of dry matter in most fresh leaves is much less than the amount of water (Féret et al., 2011), and in part because the absorption coefficient for dry matter is less than that of water (Féret et al., 2008; Jacquemoud et al., 2009). However, at about 1722-nm wavelength, the absorption coefficient of dry matter in the PROSPECT model is about equal to that of water (Féret et al., 2008; Jacquemoud et al., 2009), which is why this wavelength was selected for NDMI (Wang et al., 2011a, 2011b). One of the wavelengths used by DMCI $(1495 \mathrm{~nm})$ is located at the edge of a strong water vapor absorption feature (Green et al., 1998); therefore, it will be harder to use with data from airborne and satellite sensors. Four of the dry-matter indices used in this study were originally developed for the remote sensing of crop residue on the soil surface (NDTI, CAI, LCA, and SINDRI; Table 1). Lignin and cellulose are major components of dry matter, and indices based on absorption features from $2100 \mathrm{~nm}$ to $2500 \mathrm{~nm}$ wavelengths are correlated to leaf dry-matter content (Romero et al., 2012). However at these wavelengths, the absorption coefficients of dry matter are high, so larger differences in FMC may be required before detection using remote sensing.

The width of the 1722-nm absorption feature for dry-matter content is small, so a requirement for determining NDMI, and hence FMC, is the availability of a narrow-band sensor with a very high signal-to-noise ratio, such as the planned NASA Hyperspectral Infrared Imager (HyspIRI) mission (National Research Council, 2007). Current research on analysis of imaging spectrometer data is directed towards inversions of radiative transfer models, which may be used to estimate FMC directly without resorting to water/dry-matter indices. However, HyspIRI has a planned 19-day repeat schedule, and with cloud cover, HyspIRI data may be acquired too infrequently for monitoring FMC. The Moderate Resolution Imaging Spectroradiometer (MODIS) and the Visible Infrared Imaging Radiometer Suite (VIIRS) sensors have several bands which may be used for water indices, but these sensors do not have the spectral resolution for determining NDMI. Current data fusion methods, such as STARFM which combines Landsat and MODIS data (Gao et al., 2006), require both sensors to have similar bands, so it is unlikely that these methods will provide HyspIRI spectral resolution at VIIRS temporal resolution. Therefore, future FMC monitoring by remote sensing could be accomplished with combination of water indices from many different sensors and NDMI from HyspIRI. 


\section{Conclusions}

FMC is the ratio of water content to dry-matter content; therefore, we hypothesized that the ratio of a water index to a dry-matter index would better estimate FMC than either index alone. The results of leaf spectral reflectance data and simulations using the PROSPECT and SAIL models showed that the ratio of the water index NDII with the dry-matter index NDMI was strongly related to FMC. We also hypothesized that the effects of leaf area and other canopy variables for predicting FMC would be reduced with a NDII/NDMI ratio, but SAIL model simulations did not support this second hypothesis. NDMI requires narrow-band data to measure the effect of dry matter on reflectance at $1722 \mathrm{~nm}$, so monitoring FMC requires either a new sensor or a combination of two sensors, one with high temporal resolution for water content and one with high spectral resolution for dry-matter content.

\section{Acknowledgments}

We thank John Schroeder, Fenan Solomon and Travis Holben for making the spectral reflectance measurements. Furthermore, we thank the reviewers of this manuscript for their important and helpful comments.

\section{References}

Ceccato, P., Leblon, B., Chuvieco, E., Flasse, S., \& Carlson, J. D. (2003). Estimation of live fuel moisture content. In E. Chuvieco (Ed.), Wildland fire danger estimation and mapping (pp. 63-90). New Jersey: World Scientific.

Chuvieco, E., Riaño, D., Aguado, I., \& Cocero, D. (2002). Estimation of fuel moisture content from multitemporal analysis of Landsat Thematic Mapper reflectance data: Applications in fire danger assessment. International Journal of Remote Sensing, 23, 2145-2162.

Daughtry, C. S. T. (2001). Discriminating crop residues from soil by shortwave infrared reflectance. Agronomy Journal, 93, 125-131.

Daughtry, C. S. T., Hunt, E. R., Jr., Doraiswamy, P. C., \& McMurtrey, J. E., III (2005). Remote sensing the spatial distribution of crop residues. Agronomy Journal, 97, 864-871.

Daughtry, C. S. T., Walthall, C. L., Kim, M. S., Brown de Colstoun, E., \& McMurtrey, J. E., III (2000). Estimating corn leaf chlorophyll concentration from leaf and canopy reflectance. Remote Sensing of Environment, 74, 229-239.

Delbart, N., Kergoat, L., Le Toan, T., Lhermitte, J., \& Picard, G. (2005). Determination of phenological dates in boreal regions using normalized difference water index. Remote Sensing of Environment, 97, 26-38.

Delbart, N., Le Toan, T., Kergoat, L., \& Fedotova, V. (2006). Remote sensing of spring phenology in boreal regions: A free of snow-effect method using NOAA-AVHRR and SPOT-VGT data (1982-2004). Remote Sensing of Environment, 101, 53-62.

Dennison, P. E., Roberts, D. A., Peterson, S. H., \& Rechel, J. (2005). Use of normalized difference water index for monitoring live fuel moisture. International Journal of Remote Sensing, 26, 1035-1042.

Eitel, J. U. H., Long, D. S., Gessler, P. E., \& Hunt, E. R., Jr. (2008). Combined spectral index to improve ground-based estimates of nitrogen status in dryland wheat. Agronomy Journal, 100, 1694-1702.

Féret, J. B., François, C., Asner, G. P., Gitelson, A. A., Martin, R. E., Bidel, L. P. R., et al. (2008). PROSPECT-4 and 5: Advances in the leaf optical properties model separating photosynthetic pigments. Remote Sensing of Environment, 112, 3030-3043.

Féret, J. B., François, C., Gitelson, A., Asner, G. P., Barry, K. M., Panigada, C., et al. (2011). Optimized spectral indices and chemometric analysis of leaf chemical properties using radiative transfer modeling. Remote Sensing of Environment, $115,2742-2750$.

Gao, B. -C. (1996). NDWI - A normalized difference water index for remote sensing of vegetation liquid water from space. Remote Sensing of Environment, 58, 257-266.

Gao, F., Masek, J., Schwaller, M., \& Hall, F. (2006). On the blending of the Landsat and MODIS surface reflectance: Predicting daily Landsat surface reflectance. IEEE Transactions on Geoscience and Remote Sensing, 44, 2207-2218.

Green, R. O., Eastwood, M. L., Sarture, C. M., Chrien, T. G., Aronsson, M., Chippendale, B. J., et al. (1998). Imaging spectroscopy and the Airborne Visible/Infrared Imaging Spectrometer (AVIRIS). Remote Sensing of Environment, 65, 227-248.

Haboudane, D., Miller, J. R., Tremblay, N., Zarco-Tejada, P. J., \& Dextraze, L. (2002). Integrated narrow-band vegetation indices for prediction of crop chlorophyll content for application to precision agriculture. Remote Sensing of Environment, 81, 416-426.

Hardisky, M. A., Klemas, V., \& Smart, R. M. (1983). The influence of soil salinity, growth form, and leaf moisture on the spectral radiance of Spartina alterniflora canopies. Photogrammetric Engineering and Remote Sensing, 49, 77-83.

Hardy, C. C., \& Burgan, R. E. (1999). Evaluation of NDVI for monitoring live moisture in three vegetation types of the Western U.S.. Photogrammetric Engineering and Remote Sensing, 65, 603-610.

Hunt, E. R., Jr., \& Rock, B. N. (1989). Detection of changes in leaf water content using near- and middle-infrared reflectance. Remote Sensing of Environment, 30, 43-54.
Jacquemoud, S., Verhoef, W., Baret, F., Bacour, C., Zarco-Tejada, P. J., Asner, G. P., et al. (2009). PROSPECT + SAIL models: A review of use for vegetation characterization. Remote Sensing of Environment, S56-S66 (Supplement).

Jolly, W. M. (2007). Sensitivity of a surface fire spread model and associated fire behavior fuel models to changes in live fuel moisture. International Journal of Wildland Fire, 16, 503-509.

Keane, R. E., Drury, S. A., Karau, E. C., Hessburg, P. F., \& Reynolds, K. M. (2010). A method for mapping fire hazard and risk across multiple scales and its application in fire management. Ecological Modelling, 221, 2-18.

Nagler, P. L., Daughtry, C. S. T., \& Goward, S. N. (2000). Plant litter and soil reflectance. Remote Sensing of Environment, 71, 207-215.

National Research Council (2007). Earth science and applications from space, national imperatives for the next decade and beyond. Washington, DC: The National Academies Press.

Peterson, D. L., \& Hubbard, G. S. (1992). Scientific issues and potential remote-sensing requirements for plant biochemical content. Journal of Imaging Science and Technology, 36, 446-456.

Peterson, S. H., Roberts, D. A., \& Dennison, P. E. (2008). Mapping live fuel moisture with MODIS data: A multiple regression approach. Remote Sensing of Environment, 112, 4272-4284

Riaño, D., Vaughan, P., Chuvieco, E., Zarco-Tejada, P. J., \& Ustin, S. (2005). Estimation of fuel moisture content by inversion of radiative transfer models to simulate equivalent water thickness and dry matter content: Analysis at leaf and canopy level. IEEE Transactions on Geoscience and Remote Sensing, 43, 819-826.

Roberts, D. A., Dennison, P. E., Peterson, S., Sweeney, S., \& Rechel, J. (2006). Evaluation of Airborne Visible/Infrared Imaging Spectrometer (AVIRIS) and Moderate Resolution Imaging Spectrometer (MODIS) measures of live fuel moisture and fuel condition in a shrubland ecosystem in Southern California. Journal of Geophysical Research, 111, G04S02. http://dx.doi.org/10.1029/2005JG000113.

Rollins, M. G., Keane, R. E., \& Parsons, R. A. (2004). Mapping fuels and fire regimes using remote sensing, ecosystem simulation, and gradient modeling. Ecological Applications, 14, 75-95.

Romero, A., Aguado, I., \& Yebra, M. (2012). Estimation of dry matter content in leaves using normalized indexes and PROSPECT model inversion. International Journal of Remote Sensing, 33, 396-414.

Serbin, G., Hunt, E. R., Jr., Daughtry, C. S. T., McCarty, G. W., \& Doraiswamy, P. C. (2009). An improved ASTER index for remote sensing crop residue. Remote Sensing, 1, 971-991.

Serrano, L., Peñuelas, J., \& Ustin, S. L. (2002). Remote sensing of nitrogen and lignin in Mediterranean vegetation from AVIRIS data: Decomposing biochemical from structural signals. Remote Sensing of Environment, 81, 355-364.

Sokal, R. R., \& Rohlf, F. J. (1995). Biometry, the principles and practice of statistics in biological research (3rd ed.). New York: W. H. Freeman and Company.

Tucker, C. J. (1980). Remote sensing of leaf water content in the near infrared. Remote Sensing of Environment, 10, 23-32.

Ustin, S. L., Riaño, D., \& Hunt, E. R., Jr. (in press). Estimating canopy water content from spectroscopy. Israel Journal of Plant Science.

van Deventer, A. P., Ward, A. D., Gowda, P. H., \& Lyon, J. G. (1997). Using Thematic Mapper data to identify contrasting soil plains and tillage practices. Photogrammetric Engineering and Remote Sensing, 63, 87-93.

Verhoef, W. (1984). Light scattering by leaf layers with application to canopy reflectance modelling: The SAIL model. Remote Sensing of Environment, 16, 125-141.

Wang, L., Hunt, E. R., Jr., Qu, J. J., Hao, X., \& Daughtry, C. S. T. (2011). Towards estimation of canopy foliar biomass with spectral reflectance measurements. Remote Sensing of Environment, 115, 836-840.

Wang, L., Qu, J. J., Hao, X., \& Hunt, E. R., Jr. (2011). Estimating dry matter content from spectral reflectance for green leaves of different species. International Journal of Remote Sensing, 32, 7097-7109.

Willmott, C. J. (1981). On the validation of models. Physical Geography, 2, 184-194.

Xiao, X., Boles, S., Frolking, S., Salas, W., Moore, B., III, \& Li, C. (2002). Observation of flooding and rice transplanting of paddy rice fields at site to landscape scales in China using VEGETATION sensor data. International Journal of Remote Sensing, 23, 3009-3022.

Xiao, X., Boles, S., Liu, J., Zhaung, D., \& Liu, M. (2002). Characterization of forest types in Northeastern China, using multi-temporal SPOT-4 VEGETATION sensor data. Remote Sensing of Environment, 82, 335-348.

Yebra, M., \& Chuvieco, E. (2009). Linking ecological information and radiative transfer models to estimate fuel moisture content in the Mediterranean region of Spain: Solving the ill-posed inverse problem. Remote Sensing of Environment, 113, 2403-2411.

Yebra, M., Chuvieco, E., \& Riaño, D. (2008). Estimation of live fuel moisture content from MODIS images for fire risk assessment. Agricultural and Forest Meteorology, $148,523-536$.

Yilmaz, M. T., Hunt, E. R., Jr., Goins, L. D., Ustin, S. L., Vanderbilt, V. C., \& Jackson, T. J. (2008). Vegetation water content during SMEX04 from ground data and Landsat 5 Thematic Mapper imagery. Remote Sensing of Environment, 112, 350-362.

Yilmaz, M. T., Hunt, E. R., Jr., \& Jackson, T. J. (2008). Remote sensing of vegetation water content from equivalent water thickness using satellite imagery. Remote Sensing of Environment, 112, 2514-2522.

Zarco-Tejada, P. J., Miller, J. R., Morales, A., Berjón, A., \& Agüera, J. (2004). Hyperspectral indices and model simulation for chlorophyll estimation in open-canopy tree crops. Remote Sensing of Environment, 90, 463-476.

Zarco-Tejada, P. J., Rueda, C. A., \& Ustin, S. L. (2003). Water content estimation in vegetation with MODIS reflectance data and model inversion methods. Remote Sensing of Environment, 85, 109-124. 